\title{
Physician involvement in the care of multiply injured patients: the role of guidelines and subspecialties
}

\author{
H.-C. Pape $\cdot$ Z. Balogh
}

Received: 6 March 2012/ Accepted: 16 April 2012/Published online: 17 May 2012

(C) Springer-Verlag 2012

Recently, evidence-based guidelines for the management of multiply injured patients were released [1]. These guidelines were initiated by the German Trauma Society and developed in cooperation with all other subspecialties involved in trauma care (Table 1). The fact that 11 different societies were involved in the development of these guidelines demonstrates the high degree of specialization required for modern trauma care [2]. Distinct criteria were developed in order to define the responsibilities during initial management (Table 2).

Interestingly, the information on guidelines for trauma patients is sparse. Apart from advanced trauma life support (ATLS) guidelines, or those well documented by EAST, most available treatment recommendations apply to certain injuries such as spinal fractures [3]. In view of the improvements in outcome, this is an unexpected finding [4]. Moreover, given the fact that the responsibilities of physicians dealing with multiply injured patients have changed substantially, this is even more surprising.

When John Border published his experiences on the management of polytrauma, general surgeons and orthopaedic surgeons in many countries shared part of their education [5]. The care of severely injured patients was managed by only a few services. The diagnostic procedures available did not allow for a sophisticated differentiation of

\section{H.-C. Pape $(\square)$}

Department of Trauma and Orthopaedic Surgery,

University of Aachen Medical Center, 30 Pauwels Street,

Aachen, Germany

e-mail: hpape@ukaachen.de

\section{Z. Balogh}

John Hunter Hospital and University of Newcastle,

Newcastle, NSW, Australia

e-mail: zsolt.balogh@hnehealth.nsw.gov.au the major sources of hemorrhage. Abdominal injuries were judged on the basis of diagnostic peritoneal lavage (DPL), and clinical experience often guided decision making.

Today, almost all diagnoses can be made early after admission, and the management of certain injuries has changed substantially. In several areas, exploratory surgeries have been replaced by CT scans. In fracture management, the timing of treatment and the type of orthopaedic stabilization has changed too. In the absence of adequate ICU care, many long bone fractures were left unstabilized. Early fixation became the major goal in the orthopaedic care of long bone fractures. With improvements in ventilation and the avoidance of secondary organ failure, sophisticated staged surgical management became achievable. Treatment was then guided by more complex

Table 1 Recommendations for trauma teams (from [1])

The care of multiply injured patients should be undertaken by fixed teams (emergency room teams) who work according to pre-structured plans and/or have undergone special training (grade of recommendation: A)

The basic emergency room team should consist of at least three doctors (two surgeons, one anaesthetist); at least one anaesthetist and one surgeon should be at the consultant level (grade of recommendation: A)

Trauma centres should maintain extended emergency room teams (grade of recommendation: A)

Other senior doctors needed for continued treatment of the patient should arrive within 20-30 min of being called (grade of recommendation: A)

The emergency room should be $25-50 \mathrm{~m}^{2}$ in size (per patient to be treated) (grade of recommendation: B)

The emergency room, ambulance entrance, radiology department, and surgical department should be in the same building. The helicopter landing pad should be within the hospital grounds (grade of recommendation: B) 
Table 2 Activation of internal alarm mechanisms to activate the trauma room team (from [1])

Grade of recommendation: A

Systolic blood pressure $<90 \mathrm{mmHg}$ after trauma

Penetrating injuries to the neck and torso

Gunshot wounds to the neck and torso

Glasgow Coma Scale (GCS) $<9$ after trauma

Respiratory impairment/requirement for intubation after trauma

Fracture of more than two proximal bones

Unstable chest/pelvic fractures

Amputation injury proximal to hands/feet

Spinal cord injury

Open head wound/burns $20 \%$ and grade $\geq 2 b$

Additional criteria (the trauma/emergency room team should be activated for the following additional criteria; grade of recommendation: $\mathrm{B})$

Fall from a height $(>3 \mathrm{~m})$

Road traffic accident (RTA) with frontal impact and intrusion of more than $50-75 \mathrm{~cm}$

A change in speed of delta $>30 \mathrm{~km} / \mathrm{h}$

Collision involving a pedestrian or two-wheeler, death of a driver or passenger, and/or

Ejection of a driver or passenger

algorithms that included inflammatory changes induced by major trauma.

This differentiation in clinical education has also resulted in improvements in the priorities of care. Although experts in their fields of interest, clinicians today may have to consult many other services to achieve a complete overview of the patient's condition. Further differentiation may be useful in the future, depending on the challenges of our future patients [6].

Management guidelines help orchestrate the various aspects involved.

Conflict of interest None.

\section{References}

1. Neugebauer EAM, Waydhas C, Lendemans S, Rixen D, Eikermann M, Pohlemann Th. Treatment of patients with severe and multiple traumatic injuries. Dtsch Arztebl Int. 2012;109(6):102-8. doi:10.3238/arztebl.2012.0102.

2. Stürmer KM, Raschke MJ, Burger C, Josten C, Jürgens C, Krettek C, Meffert R, Mittlmeier T, Pape HC, Marzi I. Convention of holders of university-chairs in trauma surgery: key points on terms of reference for trauma surgery in universities-structural considerations on healthcare, research and teaching. Unfallchirurg. 2010; 113(11):957-9.

3. Hierhölzer C, Bühren V, Woltmann A. Operative timing and management of spinal injuries in multiply injured patients. Eur J Trauma Emerg Surg. 2007;33(5):488-500.

4. Pape HC, Probst C, Lohse R, Zelle BA, Panzica M, Stalp M, Steel JL, Duhme HM, Pfeifer R. Predictors of late clinical outcome following orthopedic injuries after multiple trauma. J Trauma. 2010;69(5):1243-51.

5. Border JR. Death from severe trauma: open fractures to multiple organ dysfunction syndrome. J Trauma. 1995;39(1):12-22.

6. Fayaz HC, Jupiter JB, Pape HC, Smith RM, Giannoudis PV, Moran CG, Krettek C, Prommersberger KJ, Raschke MJ, Parvizi J. Challenges and barriers to improving care of the musculoskeletal patient of the future - a debate article and global perspective. Patient Saf Surg. 2011;25(5):23. 